\title{
Amnion and Chorion Membranes for Root Coverage Procedures: An In Vitro Evaluation of its Physical Characteristics
}

\author{
Annie Kitty George ${ }^{1 *}$, Yogesh Bharath Dalvi ${ }^{2}$, Bindya Balram ${ }^{1}$, Nisha KJ ${ }^{3}$ and Sukumaran Anil ${ }^{4}$ \\ ${ }^{1}$ Department of Periodontics, Pushpagiri College of Dental Sciences, Perumthuruthy, Thiruvalla, India \\ ${ }^{2}$ Pushpagiri Research Centre, Thiruvalla, India \\ ${ }^{3}$ Department of Periodontics, Vydehi Institute of Dental Sciences and Research Centre, Whitefield, Bangalore, India \\ ${ }^{4}$ Department of Periodontics, Saveetha University, Poonamallee High Road, Chennai, India \\ *Corresponding author: Annie Kitty George, Department of Periodontics, Pushpagiri College of Dental Sciences, Perumthuruthy, \\ Thiruvalla, India, Tel: +919496749734; E-mail: ksucod@gmail.com
}

Received date: June 06, 2018; Accepted date: June 26, 2018; Published date: July 02, 2018

Copyright: (C) 2018 George AK, et al. This is an open-access article distributed under the terms of the creative Commons Attribution License, which permits unrestricted use, distribution and reproduction in any medium, provided the original author and source are credited.

Citation: George AK, Dalvi YB, Balram B, Nisha KJ, Anil S. Amnion and Chorion Membranes for Root Coverage Procedures: An In Vitro Evaluation of its Physical Characteristics. Periodon Prosthodon. 2018, Vol.4 No.2:07.

\section{Abstract}

Chorion and amnion membranes are used as cost effective, allogenic substitute for the connective tissue autograft for achieving predictable root coverage. The objective of the study was to investigate the potential of amnion and chorion membranes as a substitute for the free connective tissue autograft in the bilaminar technique of root coverage. An in vitro mechanical testing and evaluation of the degradation profile of these membranes were carried out. Tensile strength, Young's modulus and elongation at break for amnion and chorion membranes were tested using universal testing machine. Suture retention and degradation tests were conducted. The tensile strength of amnion membrane is $155 \mathrm{kPa}$ and that of chorion is $95 \mathrm{kPa}$. Young's Modulus of amnion membrane is $645 \mathrm{kPa}$ and that of chorion is $335 \mathrm{kPa}$. Extension at break is $17.3 \mathrm{~mm}$ for amnion and $13.5 \mathrm{~mm}$ for chorion. The degradation profiles were expressed as mean accumulated weight losses of the membranes at the end of the first, second, third and fourth week. Chorion membrane has greater thickness and density when compared to amnion. Mechanical testing of these membranes points out that they are elastic in nature. Amnion is more elastic with higher tensile strength, Young's modulus and extension at break than chorion. In the suture retention test, amnion membrane can take up more load during suturing. In vitro degradation profiles of both membranes look promising. Amnion and chorion membranes are not totally degraded at the end of 4 weeks. In terms of in vitro degradation, amnion membranes appear to be more resistant than chorion membranes. Both membranes retain their physical form up to three weeks.

Keywords: Amnion; Chorion; Mechanical testing; Tensile strength; Young's modulus; Degradation profile

\section{Introduction}

Gingival recession is an apical shift of the gingival margin with exposure of the root surface to the oral cavity [1]. The treatment of gingival recession defects is indicated for esthetic reasons, to reduce root hypersensitivity, to create or augment keratinized tissue, in root abrasion/caries and in cases of inconsistency/disharmony of the gingival margin [2]. Recent literature indicates that the subepithelial connective tissue graft is the most predictable root coverage surgical procedure. In this 'gold standard' technique, a bilaminar vascular environment is created to nourish the graft. However, harvesting the autograft from the palatal area increases postoperative morbidity, is time consuming and only a limited amount of donor tissue is available which is insufficient for multiple recession defects [3]. Thus, there has been a desire to find a versatile substitute for the autogenous donor tissue. Acellular dermal matrix graft is an allograft which is being used in this regard [4]. Recently, newer xenogenic collagen matrices have been developed. However, there is an ongoing search for a versatile substitute for the connective tissue autograft.

Placental allografts are now emerging as a novel and versatile material in periodontal plastic surgery. The foetal membranes possess unique inherent biologic properties that enhance wound healing and may propagate regeneration. Foetal membranes possess distinctive properties that can be harnessed to promote periodontal reconstruction. Foetal membranes are comprised of amniotic and chorion tissues. Amniotic membrane has three parts which are an epithelial monolayer, a thick basement membrane, and an avascular stroma. Chorion is composed of a reticular layer, basement membrane, and trophoblasts [5]. Both chorion and amnion membranes are now being used as cost effective, allogenic substitute for the connective tissue autograft for achieving predictable root coverage [6-12]. However, their extensive use is not sufficiently supported by evidence regarding their mechanical properties and degradation profile. This study 
evaluates and compares the mechanical properties and degradation profile of amnion and chorion membranes.

\section{Materials and Methods}

This study focusses on biomechanical testing of amnion and chorion membranes for its potential application as a substitute to the connective tissue autograft in root coverage procedures. Freeze dried irradiated amnion and chorion membranes were purchased from the Tissue bank of Tata Memorial hospital (Figure 1). Preparation of amnion and chorion membrane: In the production of the amnion and chorion allograft used in this study, pre-screened, consenting mothers donated the amnion and associated tissues during elective caesarean section surgery. All donated tissue follows strict guidelines for procurement, processing, and distribution, as dictated by the Tissue Bank, (Tata Memorial Hospital, Mumbai). These safety measures include testing for serological infectious diseases such as human immunodeficiency virus (HIV) type 1 and 2 antibodies, human T-lymphotropic virus type 1 and 2 antibodies, hepatitis $C$ antibody, hepatitis B surface antigen, hepatitis B core total antibody, serological test for syphilis, HIV type 1 nucleic acid test, and hepatitis $C$ virus nucleic acid test. Upon collection of the maternal tissue, the amnion and chorion tissues were carefully separated, and cleansed prior to processing. The allografts were dehydrated, perforated, and terminally sterilized.

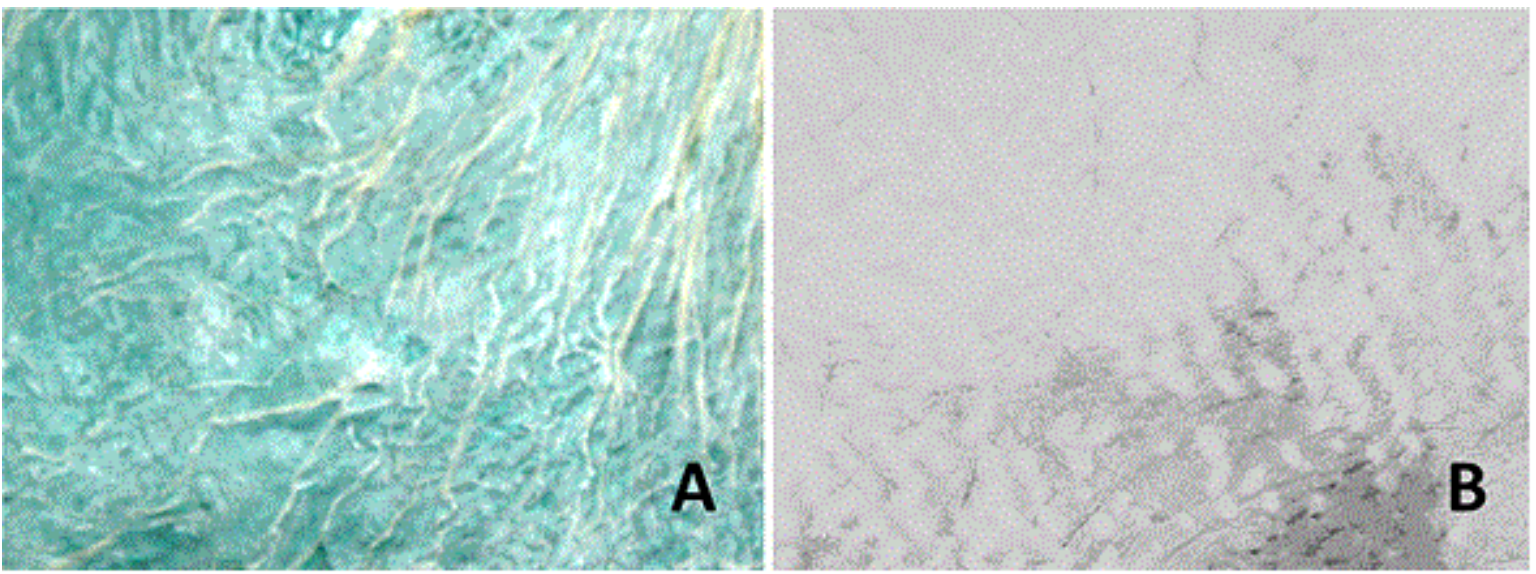

Figure 1 Photograph showing the membrane. A: Amnion and B: Chorion.

Mechanical testing of the membranes was carried out at the Biomedical wing of the Sree Chitra Tirunal Institute of Medical Sciences and Technology, Thiruvananthapuram. The average dimensions of the five amnion membranes were $7.2 \times 4.7 \mathrm{~cm}$ and that of 5 chorion membranes were $8 \times 6.5 \mathrm{~cm}$. The thickness of each amnion and chorion membranes were recorded at two different points using a digital calliper (Baker. 002-.5 mm, Type J11). The average of the ten thickness measurements each of both the amnion and chorion membranes were calculated. The weights of each of the amnion and chorion membranes were recorded using an electronic micro weighing scale. The product of length, breadth and thickness gives the volume measure. Two volume measures corresponding to the two thickness measures were obtained for each membrane. Weight/volume gives the density of the membranes. Ten measurements for density for both amnion and chorion membranes were calculated.

Prior to mechanical testing ten strips of $5 \times 1 \mathrm{~cm}$ were cut from both amnion and chorion (two from each amnion and chorion membranes) The membrane strips were immersed in phosphate buffered saline solution for fifteen minutes prior to mechanical testing. The instrument used for mechanical testing was Instron, model 3345. Guage length (distance between the clamps) used was $3 \mathrm{~cm}$. During testing, a longitudinal strain is applied at a constant rate along the main size of the rectangular specimen. Test speed was $1 \mathrm{~mm} / \mathrm{mt}$ with a load cell of $100 \mathrm{~N}$. Tensile strength, Young's modulus and elongation at break were calculated. Suture retention test was carried out. In the suture retention test, ten strips each of both amnion and chorion of dimensions $10 \mathrm{~mm} \times 3 \mathrm{~cm}$ were cut out. In the universal testing machine, the lower part of the membrane is inserted into the lower clamp and upper part of the membrane is left free. At $0.2 \mathrm{~mm}$ from the upper aspect of the membrane a suture is inserted into the membrane and then into the upper clamp and pulled upwards at a speed of 1 $\mathrm{mm} / \mathrm{min}$. The suture is pulled till the membrane ruptured. Maximum load prior to rupture of membranes is recorded and this gives the maximum load which can be applied during suturing.

In vitro degradation profile of the foetal membranes was carried out at the Pushpagiri Research Centre. The in vitro degradation tests of the prepared membranes were conducted by placing three strips of each membranes, of size $10 \times 5 \mathrm{~mm}$ in $5 \mathrm{~mL}$ of $\mathrm{pH}$ 7.4 PBS on a shaker set (Orbital Kahn Shaker) at $40 \mathrm{rpm}$. All the membranes were weighed on an electronic micro weighing scale at baseline after hydration and at the end of 1st, 2nd, 3rd and 4th week. The degradation profiles were expressed as the accumulated weight losses of the membranes.

Statistical analysis: Data was analysed and presented as mean, standard deviation and median. The comparison 
between amnion and chorion were done by Mann-Whitney $U$ test. A $p$ value of $<0.05$ is considered as statistically significant.

\section{Results}

Average thickness of amnion membrane was $0.43 \pm 0.07$ $\mathrm{mm}$ surface density was $0.093 \pm 0.006 \mathrm{gm} / \mathrm{cm}^{3}$. Average thickness of chorion membrane was $1.66 \pm 0.644 \mathrm{~mm}$ and density were $0.201 \pm 0.17 \mathrm{gm} / \mathrm{cm}^{3}$. Tensile strength of amnion was $155 \pm 65 \mathrm{kPa}$, Young's modulus was $645 \pm 211 \mathrm{kPa}$ and elongation at break was $17.3 \pm 2.03 \mathrm{~mm}$. Tensile strength of chorion was $95 \pm 14.7 \mathrm{kPa}$, Young's modulus was $335 \pm 53 \mathrm{kPa}$ and elongation at break was $13.5 \pm 1.63 \mathrm{~mm}$. Maximum load which can be applied during suturing for amnion is $0.123 \pm$ 0.037 Newtons and for chorion is $0.052 \pm 0.005 \mathrm{~N}$ (Table 1). Amnion membranes degraded $21 \%$ of its initial weight at the end of the first week, $24.1 \%$ at the end of second week, $31.35 \%$ at the end of the third week and $70 \%$ at the end of four weeks. Chorion membranes degraded $29 \%$ of its initial weight at the end of the first week, $35 \%$ at the end of the second week, $42 \%$ at the end of the third week and $84 \%$ at the end of the fourth week.

Table 1 Comparison of the mechanical properties of the Amnion and Chorion membranes.

\begin{tabular}{|l|l|l|l|}
\hline Mechanical Properties & Amnion & Chorion & $\begin{array}{l}\text { P } \\
\text { value }\end{array}$ \\
\hline & Mean \pm SD & Mean \pm SD & \\
\hline Thickness (mm) & $0.43 \pm 0.08$ & $1.67 \pm 0.64$ & $\begin{array}{l}\mathrm{P}=0.00 \\
1^{*}\end{array}$ \\
\hline $\begin{array}{l}\text { Surface density (grm/ } \\
\mathbf{c m}^{3} \text { ) }\end{array}$ & $0.09 \pm 0.01$ & $0.20 \pm 0.17$ & $\mathrm{P}=0.99$ \\
\hline Tensile strength (MPa) & $0.16 \pm 0.07$ & $0.10 \pm 0.01$ & $\begin{array}{l}\mathrm{P}=0.08 \\
9\end{array}$ \\
\hline Young's modulus (MPa) & $0.65 \pm 0.21$ & $0.34 \pm 0.05$ & $\begin{array}{l}\mathrm{P}=0.00 \\
1^{*}\end{array}$ \\
\hline Elongation at break (mm) & $17.33 \pm 2.04$ & $13.57 \pm 1.63$ & $\begin{array}{l}\mathrm{P}=0.00 \\
1^{*}\end{array}$ \\
\hline Suture retention load (N) & $0.12 \pm 0.04$ & $0.05 \pm 0.01$ & $\begin{array}{l}\mathrm{P}=0.00 \\
1^{*}\end{array}$ \\
\hline *statistically significant & & & \\
\hline
\end{tabular}

\section{Discussion}

The sub epithelial connective tissue graft is the gold standard surgical technique in the management of isolated gingival recessions. However, harvesting the autogenous connective tissue from the palate increases postoperative morbidity, is time consuming and only a limited amount of donor tissue is available for multiple recession defects. Thus, there is an ongoing search to find a substitute for the autogenous donor tissue [3]. The acellular dermal matrix graft has been used as a substitute for connective tissue grafts in root coverage procedures $[4,13]$. Xenogenic collagen matrices have been developed and tried in this regard [14,15]. A new collagen matrix of porcine origin (Mucografts Prototype) has also been developed [16]. Foetal membranes are now being increasingly used in periodontal reconstructive procedures especially in root coverage. Foetal membranes have antiinflammatory, anti-scarring, anti-microbial properties, they have low immunogenicity and is a reservoir of stem cells and growth factors. They also enhance wound healing and angiogenesis [17].

Though there is ample evidence in literature regarding their biologic properties, lacunae exist regarding their mechanical properties and degradation profile. This study provides clear evidence on the mechanical properties and degradation profile of amnion and chorion membranes. The average thickness of amnion at ten different sites drawn from multiple samples is $0.43 \mathrm{~mm}$ and that of chorion is $1.66 \mathrm{~mm}$ and their density is $0.093 \mathrm{~g} / \mathrm{cm}^{3}$ and $0.201 \mathrm{~g} / \mathrm{cm}^{3}$ respectively. Rao and Chandrasekharan [18] reported that the thickness of amnion ranges from 0.02 to $0.5 \mathrm{~mm}$ and that, one of the major advantages of foetal membranes in comparison to other biodegradable membranes, is their thinness and good adaptability. The thickness of the human term amnion varies among individuals and also depends on the location of the sample. Results of our study indicate statistically significant difference in the thickness of amnion and chorion and increased thickness of chorion. In proportion to thickness, differences were found in density of amnion and chorion membranes. Higher thickness results in more material per surface unit.

Amnion is composed of five distinct layers, including the epithelium, basement membrane, compact layer, fibroblast layer, and intermediate or spongy layer. The basement membrane is mainly composed of collagens III and IV [19]. Interstitial collagens I and III form bundles in the compact layer that maintain the mechanical integrity of the membrane, whereas collagens $\mathrm{V}$ and $\mathrm{VI}$ form filamentous connections to the basement membrane. The fibroblast layer is the thickest layer of the amnion. Chorion is composed of a reticular layer, basement membrane, and trophoblast layer. The reticular layer forms a majority of chorion's thickness [7]. The reticular network is composed of collagens I, III, IV, V, and VI. Chorion is three to four times thicker than amnion [20]. The basement membrane anchors the trophoblasts to the reticular layer with collagen IV, fibronectin, and laminin [21].

Mechanical testing reveals that the foetal membranes are elastic. Amniotic membranes have a tensile strength of 155 $\mathrm{kPa}$ and chorion membranes have a tensile strength of $95 \mathrm{kPa}$. The elongation at break displayed by amnion is $17 \mathrm{~mm}$ and that of chorion is $13.5 \mathrm{~mm}$. Amnion is more elastic than chorion with a higher tensile strength, Young's modulus and greater extension at break. Amnion is privileged by nature to withstand the progressive stretching of the growing embryo, internal and external traumas, and fast and slow pressure changes. Our results are in accordance with an earlier study which showed that the strength of the intact chorioamniotic membrane is primarily determined by the amniotic membrane [22]. The Young's modulus is a measure of elasticity which is normally applied in mechanical physics and is defined as the ratio of applied stress to strain. In our study, The Young's 
modulus of amnion is $645 \mathrm{kPa}$ and of chorion is $335 \mathrm{kPa}$. Benson-Martin et al. reported that Young's modulus of preterm (26-36 weeks) human amniotic membrane is $3.6 \mathrm{MPa}$, whereas this modulus for term (36-40 weeks) human AM is 2.29 MPa. Kiviranta et al. [23] reported that the elasticity, stiffness and other biomechanical properties of the extracellular matrix of the foetal membranes depend on the variation in its ingredients, such as collagen, proteoglycan and elastin [23,24].

The ability of this allograft to self-adhere eliminates the need for suturing thus making it easier to use in posterior defects [9]. However, if need for suturing arises as in areas of complex anatomic features, sutures can help stabilize these membranes. The suture retention load for amnion was $12 \mathrm{~N}$ and for chorion was $0.5 \mathrm{~N}$. The results indicate that higher suture retention loads can be tolerated by amnion when compared to chorion. In vitro degradation revealed that both the membranes resist degradation and maintain their physical form up to three weeks. Foetal membranes degrade completely. Amnion membranes are not totally degraded even at the end four weeks. The accumulated weight loss in percentage for the amnion membrane was $21 \%$ of its initial weight at the end of the first week, $24 \%$ of the initial weight at the end of second week, $31 \%$ at the end of third week and $70 \%$ at the end of the fourth week. Chorion membrane degraded $29 \%$ of its initial weight at the end of the first week, $35 \%$ at the end of the second week, $42 \%$ at the end of the third week and $84 \%$ at the end of the fourth week.

Bunyaratavej and Wang [25] reported that collagen-based membranes have unpredictable resorption rates, which can vary from 4 to 24 weeks. They also stated that non-cross-linked collagen membranes have a half-life that varies between 7 and 28 days. Most resorbable membranes degrade during a period of four to eight weeks [26]. Proteolytic degradation could accelerate degradation in vivo but when membranes are used in the bilaminar technique for root coverage, the sandwiched location beneath the flap could delay degradation in vivo. Results of our study agree with reports of Chopra and Thomas [27] who reported that foetal membranes are degraded by about four weeks. Bozkurt et al. [28] reported that collagen membranes could take 4 weeks to achieve structural integrity in periodontal regeneration.

Periodontal wound healing/regeneration largely appears complete within 2-3 weeks of wound closure, to be followed by remodelling/tissue maturation to meet functional demands [29]. In this context, biomaterials like foetal allografts targeting regeneration definitely serve their purpose in root coverage if they can retain their physical form for a period of 2-3 weeks. Pollard et al. [30] attributed that the resistance of amnion membranes to degradation was due to the presence of interstitial collagens.

When foetal membranes are used as a substitute to connective tissue autografts, they are sandwiched between the root surface and the overlying vascular flap. In this unique positioning, a film of blood clot could be stabilised, protected from a down growing epithelium, and allowed to mature in the initial 2-3 weeks. Limitations of this study was the inherent biologic nature of these membranes. Thickness differs at different areas. Malak and Bell [31] reported areas of unique morphological features, which were only found within a restricted area, termed as "zone of altered morphology" (ZAM). These areas are structurally weak and are to be discarded. The amnion membrane samples and chorion samples tested do not reveal identical degradation rates. Foetal membranes lack rigidity and they could collapse into the defect when not supported by a graft if they are used as barrier membranes in guided tissue regeneration.

The mechanical properties of these membranes and adequate stability to in vitro degradation do support their use as allogenic alternatives to the connective tissue autograft in the bilaminar technique of root coverage. Their excellent biologic properties can be backed up by evidence regarding their mechanical properties and in vitro degradation profile. Amnion membranes are more elastic with greater tensile strength, Young's modulus and extension at break than the thicker and denser chorion membranes. Amnion membranes can also bear greater suture retention loads. Amnion membranes also degrade slower than chorion. However, both membranes retain their physical form for up to three weeks. These data together definitely do support their use in periodontal reconstruction. Foetal membranes are cost effective and easily available. More clinical and histologic studies are needed to facilitate the effective and evidencebased use of foetal membranes in root coverage procedures.

\section{Conflict of Interest and Source of Funding}

None. The study was funded by the author herself.

\section{Acknowledgements}

We acknowledge Rev. Father, Dr. Mathew Mazhavancheril, Director of Academics and Research, Pushpagiri group of institutions and the Pushpagiri research centre. We also acknowledge Ruby, Research fellow, for her timely help in carrying out this study. We also acknowledge the help rendered by Nisha, Assistant professor and Biostatistician, Pushpagiri institute of medical sciences and research centre and Dr. Vivek Narayanan, PG Resident, Govt. dental college, Kottayam for the statistical analysis of this study. The authors wish to acknowledge the Sree Chitra Tirunal Institute for medical science and technology and Dr. Roy Joseph, Scientist G. The help rendered by Jinzy Antony of SCT and Arun Abraham John is much appreciated.

\section{References}

1. Patel M, Nixon PJ, Chan MF (2011) Gingival recession: Part 1. Aetiology and non-surgical management. $\mathrm{Br}$ Dent J 211: 251-254.

2. Cairo F, Pagliaro U, Nieri M (2008) Treatment of gingival recession with coronally advanced flap procedures: a systematic review. J Clin Periodontol 35: 136-162. 
3. Joly JC, Carvalho AM, da Silva RC, Ciotti DL, Cury PR (2007) Root coverage in isolated gingival recessions using autograft versus allograft: a pilot study. J Periodontol 78: 1017-1022.

4. Barker TS, Cueva MA, Rivera-Hidalgo F, Beach MM, Rossmann JA, et al. (2010) A comparative study of root coverage using two different acellular dermal matrix products. J Periodontol 81: 1596-1603.

5. Niknejad H, Peirovi $H$, Jorjani $M$, Ahmadiani A, Ghanavi J, et al. (2008) Properties of the amniotic membrane for potential use in tissue engineering. Eur Cell Mater 15: 88-99.

6. Suresh D, Gupta A (2013) Gingival biotype enhancement and root coverage using Human Placental Chorion membrane. Clin Adv Periodon 3: 237-242.

7. Shetty SS, Chatterjee A, Bose S (2014) Bilateral multiple recession coverage with platelet-rich fibrin in comparison with amniotic membrane. J Indian Soc Periodontol 18: 102-106.

8. Singh $H$, Singh $H$ (2013) Bioactive amnion as a guided tissue regeneration (GTR) membrane for treatment of isolated gingival recession. A case reports. Indian J Dent 4: 110-113.

9. Holtzclaw DJ, Toscano NJ (2013) Amnion-chorion allograft barrier used for guided tissue regeneration treatment of periodontal intrabony defects: A retrospective observational report. Clin Adv Periodon 3: 131-137.

10. Gurinsky B (2009) A novel dehydrated amnion allograft for use in the treatment of gingival recession: An observational case series. J Implant Advan Clin Dent 1: 65-73.

11. Sharma A, Yadav K (2015) Amniotic membrane - A Novel material for the root coverage: A case series. J Indian Soc Periodontol 19: 444-448.

12. Esteves J, Bhat KM, Thomas B, Varghese JM, Jadhav T (2015) Efficacy of Human Chorion Membrane Allograft for Recession Coverage: A Case Series. J Periodontol 86: 941-944.

13. Chambrone L, Chambrone D, Pustiglioni FE, Chambrone LA, Lima LA (2008) Can subepithelial connective tissue grafts be considered the gold standard procedure in the treatment of Miller Class I and II recession-type defects? J Dent 36: 659-671.

14. McGuire MK, Scheyer ET (2010) Xenogeneic collagen matrix with coronally advanced flap compared to connective tissue with coronally advanced flap for the treatment of dehiscence-type recession defects. J Periodontol 81: 1108-1117.

15. McGuire MK, Scheyer ET (2016) Long-Term Results Comparing Xenogeneic Collagen Matrix and Autogenous Connective Tissue Grafts With Coronally Advanced Flaps for Treatment of Dehiscence-Type Recession Defects. J Periodontol 87: 221-227.

16. Cardaropoli D, Tamagnone L, Roffredo A, Gaveglio L (2012) Treatment of gingival recession defects using coronally advanced flap with a porcine collagen matrix compared to coronally advanced flap with connective tissue graft: a randomized controlled clinical trial. J Periodontol 83: 321-328.
17. Agarwal A, Shankar S, Singh G, Saxena P, Tahseen A (2014) Pleiotropic properties of amniotic membrane for modulation of periodontal healing. Int J Dent Med Res 1: 110-117.

18. Rao TV, Chandrasekharam V (1981) Use of dry human and bovine amnion as a biological dressing. Arch Surg 116: 891-896.

19. Parry S, Strauss JF (1998) Premature rupture of the fetal membranes. N Engl J Med 338: 663-670.

20. Oyen ML, Cook RF, Calvin SE (2004) Mechanical failure of human fetal membrane tissues. J Mater Sci Mater Med 15: 651-658.

21. Bourne $G$ (1962) The foetal membranes. A review of the anatomy of normal amnion and chorion and some aspects of their function. Postgrad Med J 38: 193-201.

22. Oxlund H, Helmig R, Halaburt JT, Uldbjerg N (1990) Biomechanical analysis of human chorioamniotic membranes. Eur J Obstet Gynecol Reprod Biol 34: 247-255.

23. Kiviranta P, Rieppo J, Korhonen RK, Julkunen P, Toyras J, et al. (2006) Collagen network primarily controls Poisson's ratio of bovine articular cartilage in compression. J Orthop Res 24: 690-699.

24. Benson-Martin J, Zammaretti P, Bilic G, Schweizer T, PortmannLanz B, et al. (2006) The Young's modulus of fetal preterm and term amniotic membranes. Eur J Obstet Gynecol Reprod Biol 128: 103-107.

25. Bunyaratavej $P$, Wang HL (2001) Collagen membranes: a review. J Periodontol 72: 215-229.

26. Mellonig JT, Nevins M, Sanchez R (1998) Evaluation of a bioabsorbable physical barrier for guided bone regeneration. Part I. Material alone. Int J Periodontics Restorative Dent 18: 139-149.

27. Chopra A, Thomas BS (2013) Amniotic membrane: A novel material for regeneration and repair. Biomimetics Biomaterials and Tissue Engineering 18: 1-8.

28. Bozkurt A, Apel C, Sellhaus B, van Neerven S, Wessing B, et al. (2014) Differences in degradation behavior of two non-crosslinked collagen barrier membranes: an in vitro and in vivo study. Clin Oral Implants Res 25: 1403-1411.

29. Dickinson DP, Coleman BG, Batrice N, Lee J, Koli K, et al. (2013) Events of wound healing/regeneration in the canine supraalveolar periodontal defect model. J Clin Periodontol 40: 527-541.

30. Pollard SM, Aye NN, Symonds EM (1976) Scanning electron microscope appearances of normal human amnion and umbilical cord at term. Br J Obstet Gynaecol 83: 470-477.

31. Malak TM, Bell SC (1994) Structural characteristics of term human fetal membranes: a novel zone of extreme morphological alteration within the rupture site. $\mathrm{Br} \mathrm{J}$ Obstet Gynaecol 101: 375-386. 